\title{
Application of Computer Data Analysis Technology in the Development of a Physical Education Examination Platform
}

\author{
https://doi.org/10.3991/ijet.v14.i06.10158 \\ Fan Cheng, Yiwei Yin $\left({ }^{(}\right)$ \\ Yibin University, Yibin, China \\ yinyiwei427@sina.com
}

\begin{abstract}
This physical education assessment platform is designed based on the data mining technology to address a number of problems like large workload in the actual physical education performance examination of school students so as to help teachers offer individualized teaching. In the design and development of the computer-data-analysis-based physical education assessment platform, this paper adopts the ASP.NET technology and employs the threelayer architecture. The application of this platform can help solve the problems currently existing in the physical education management and realize information-based and automated physical education performance examination.
\end{abstract}

Keywords-Physical education performance, data analysis, web, decision tree

\section{$1 \quad$ Introduction}

At present, many colleges and universities provide physical education (P.E.) courses for students and also examine their performance [1-3]. Usually colleges only archive these examination results into the school information database without conducting systematic analysis and management on these exam results according to the health status of each student or giving the analysis and feedback results to the students. As a result, students only take physical fitness exam in physical education class and do not know well about their health status, nor do they understand what to improve physically [4-6]. Therefore, the college P.E. examination has no practical use although it takes time and energy [7-9].

In order to address the above problems in P.E. teaching, there is an urgent need for an information-based P.E. examination management platform that can scientifically analyze the results after each P.E. examination. This platform will reduce P.E. teachers' workload and at the same time make the examination results more useful because these result can help students develop good physical exercise habits and strengthen their physical fitness. In this way, P.E. teaching quality can be guaranteed. 


\section{Theoretical and Technological Basis}

\subsection{Web technology}

ASP.NET: ASP.NET evolved from the ASP technology. It is a whole new development technology that incorporates the features of .ASP and .NET [10-12]. In data processing, in order to improve the computation speed and efficiency, the application layer of the ASP.NET technology is divided into three layers: the user layer oriented to users, the middle business logic layer, and the data access layer for data service. The model of the three-layer structure is shown in Figure 1.

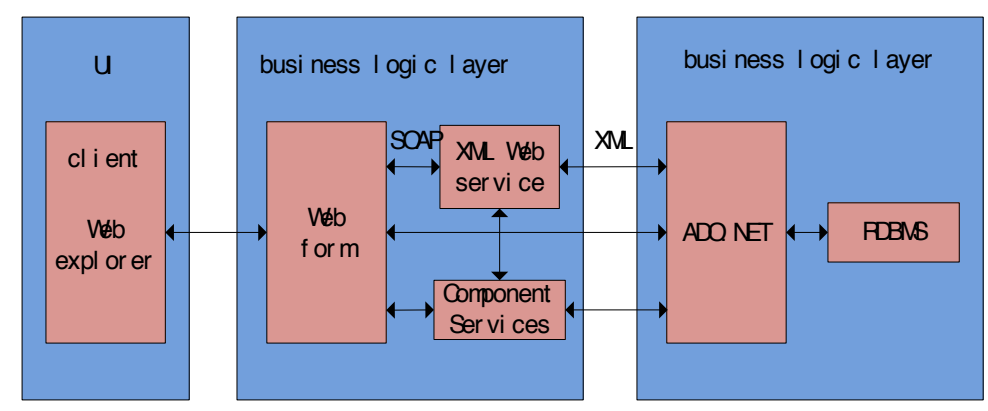

Fig. 1. Three-decker based on ASP.NET

SQL Server database: This paper selects the mature SQL Server2005 as the database platform for the P.E. performance examination platform, because, in addition to higher reliability, the SQL Server database also uses a distributed view, which greatly improves the database access speed and efficiency and also helps users quickly locate the data location. Besides, it also supports various development languages including XML; with multiple commonly used technologies encapsulated, the database can integrate data to the greaexam extent; at last, it can provide system network interfaces to the users.

\subsection{Data mining}

The data mining technology can automatically conduct scientific statistics and analysis of the given data and then predict the pattern of the data using an appropriate algorithm. This prediction result is just the potential information excavated under the data mining technology. It is valuable data, showing the predicted future trend and development of relevant data [13-14].

\subsection{Decision tree theory}

Decision tree is a top-down recursive data sorting method. According to the tree model, it conducts the exam from root nodes to branch nodes. During the exam, it first 
compares the corresponding attributes of all nodes on the decision tree and at the same time make decisions on the branches connected to each node. In this way, it can work out a path straight to a leaf node, and through this path, it can obtain the conclusions needed [15].

\section{$3 \quad$ Platform Analysis}

\subsection{Requirement analysis}

The proposed platform consists of five modules: an exam type management function module an exam item management function module a score management function module a score analysis and statistics module and a platform administration function module. It is geared to three types of users:

- One is the platform administrators, who can operate all functions in the platform;

- Second is students, who can only operate the score module

- Third is P.E. teachers, who can operate all functions except the system administration module.

\subsection{Data flow analysis}

Data flow analysis is a process where the given data are operated as designed and processed as required, or the process of platform implementation. If data flow graphs are used to describe it, it can be divided into a top-level flow graph, a level-0 flow graph, and a level-1 flow graph, as shown in Figure 2.

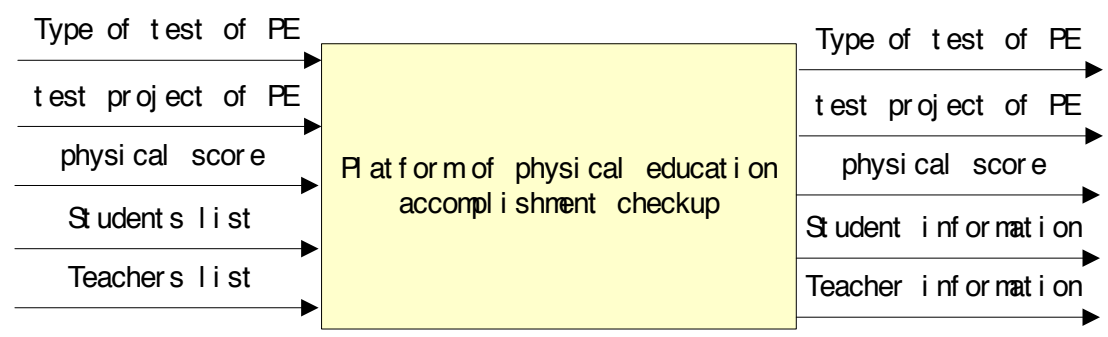

Fig. 2. Top level data flow of performance evaluation of PE

It can be seen from Figure 2 that the data directed to the proposed platform include exam type, exam item, student's score, list of students in the class and list of teachers. When all data reach the P.E. exam result assessment platform, they will be processed by the proposed platform into the data and information shown on the right side of the figure, and then fed back to the target users. 


\section{$4 \quad$ Platform Design}

\subsection{Overall architecture of the platform}

The overall technical architecture of the .NET three-layer structure used by the proposed platform is shown in Figure 3.

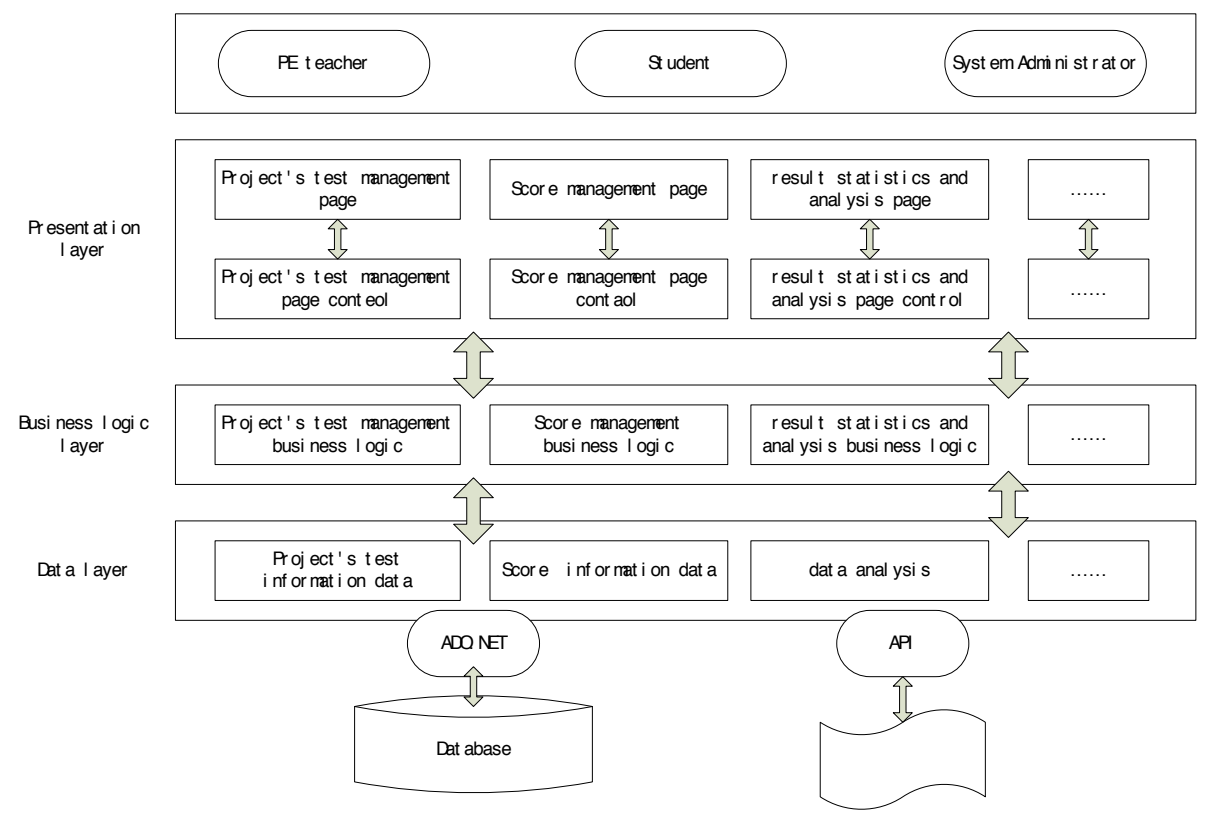

Fig. 3. The overall technical architecture for platform

It can be seen from the figure that the proposed platform divides the whole application layer into three parts: the control page is located at the top level, mainly serving users like P.E. teachers, students and platform administrators; the second layer is the business logic layer, which can carry out logical judgments and execution and also interact with the underlying data access layer in the platform implementation process; the underlying data access layer; the underlying data access layer is responsible for the interaction of all databases and execution and processing of all data requests.

\subsection{Platform function module design}

Function module division: According to the division of platform functional modules, the overall functional structure diagram of the proposed platform is designed as follows: 


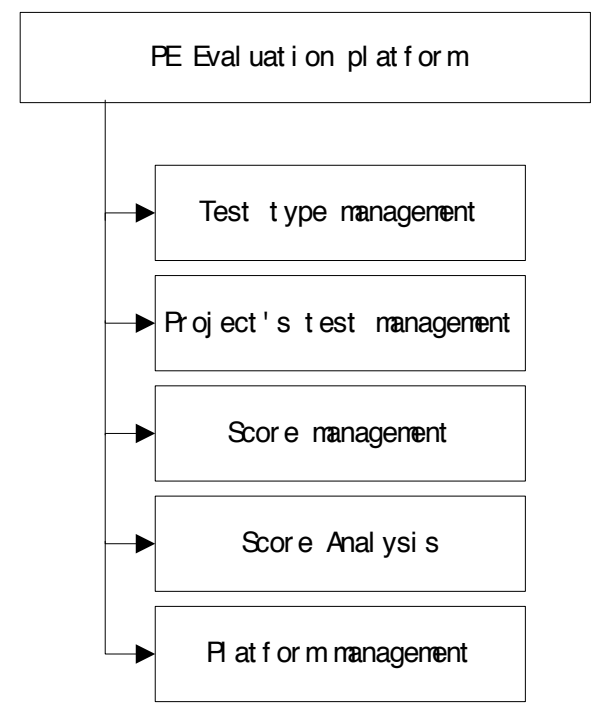

Fig. 4. Overall functional structure for platform

It can be seen from Fig. 4 that the proposed platform can be divided into several management modules by function, namely exam type, exam item, score management, score analysis and system administration.

Exam type refers to the type of physical exam provided in the teaching program. Exam type management involves operations like addition, modification, deletion and score weight setting.

Exam items refer to specific sport items often involved in the P.E. examinations like high jump, shot and long-distance running, so exam item management is just the actual management on the contents of these examination items, including operations like addition, modification, deletion and weight setting.

Score management mainly includes the entry, modification, deletion, inquiry, export and conversion of examination scores. Anything related to students' P.E. scores are in this module.

The score statistical and analysis function is the core function of the whole platform. It first takes statistics of the students' P.E. scores, works out the statistical results and presents them in the form of diagram or text, and then conducts relevant analysis using the data mining algorithm.

Platform administration is mainly used to administer and maintain all the basic information on the platform, such as the addition, modification and deletion of users and backup and restoration, modify and delete, the allocation of permissions and database backup and restoration.

\subsection{Database design}

Each of the entities involved in the database design for the proposed platform, like user information, student information, exam type, exam item, exam score and perfor- 
mance information can be expressed in the E-R diagram. Then the ER diagrams are converted on a one-to-one basis. After the conversion, the logical relationship models can be obtained and then the data table can be designed.

Through conversion of the E-R diagrams of the P.E. examination platform, 6 relationship models are obtained for user information, student information, exam type, exam item, exam score and performance information, respectively. With these relationship models, the data table can be designed next.

Table 1 is the user information table, which contains all the platform-related user information, such as ID, user name, user type and password.

Table 1. User message table

\begin{tabular}{|l|l|c|c|l|}
\hline \multicolumn{1}{|c|}{ Field name } & Data type (length) & $\begin{array}{c}\text { Whether primary } \\
\text { key }\end{array}$ & Whether allow null & \multicolumn{1}{c|}{ Description } \\
\hline YongHuID & Int & Yes & No & User ID \\
\hline YongHuMing & varchar (20) & No & No & User name \\
\hline MiMa & varchar (20) & No & Yes & login password \\
\hline LeiXing & Bit & No & No & user type \\
\hline
\end{tabular}

\subsection{Decision tree construction algorithm}

The construction algorithm of the decision tree can be completed with the training set $\mathrm{T}$, where $\mathrm{T}=\{<\mathrm{x}, \mathrm{Cj}\rangle\}$ and $\mathrm{x}=\left(\mathrm{a}_{1}, \mathrm{a}_{2} \ldots \mathrm{a}_{\mathrm{n}}\right)$ is a training instance with $\mathrm{n}$ attributes listed in the attribute table (A1, A2, An), where ai represents the value of the attribute Ai. $C_{j} \in C=\left\{C_{1}, C_{2}, C_{m}\right\}$ is the classification result of $X$. The algorithm is divided into the following steps:

Select the attribute Ai from the attribute table as the classification attribute;

If the attribute $\mathrm{Ai}$ has $\mathrm{Ki}$ values, then divide $\mathrm{T}$ into $\mathrm{Ki}$ subsets $\mathrm{T} 1 \ldots \mathrm{Tk}$,

Where, $\mathrm{T}_{\mathrm{ij}}=\{\langle\mathrm{x}, \mathrm{C}>|<\mathrm{x}, \mathrm{c}>\} \in \mathrm{T}$, and the attribute value $\mathrm{A}$ of $\mathrm{X}$ is the $\mathrm{Ki}$-th value;

Delete the attribute Ai from the attribute table;

For each $\mathrm{T}_{\mathrm{ij}}(1 \leq \mathrm{j} \leq \mathrm{K} 1)$, let $\mathrm{T}=\mathrm{T}_{\mathrm{ij}}$;

If the attribute table is not null, return to (1), otherwise output the result.

\section{$5 \quad$ Platform implementation}

\subsection{Implementation of P.E. performance examination}

P.E. exam items: the program flow of the P.E. exam item management is shown in Figure 5.

Part of the key codes for implementing platform functions are as follows. The user calls AddProject to operate the database after the information input on the page is fetched by the program. 


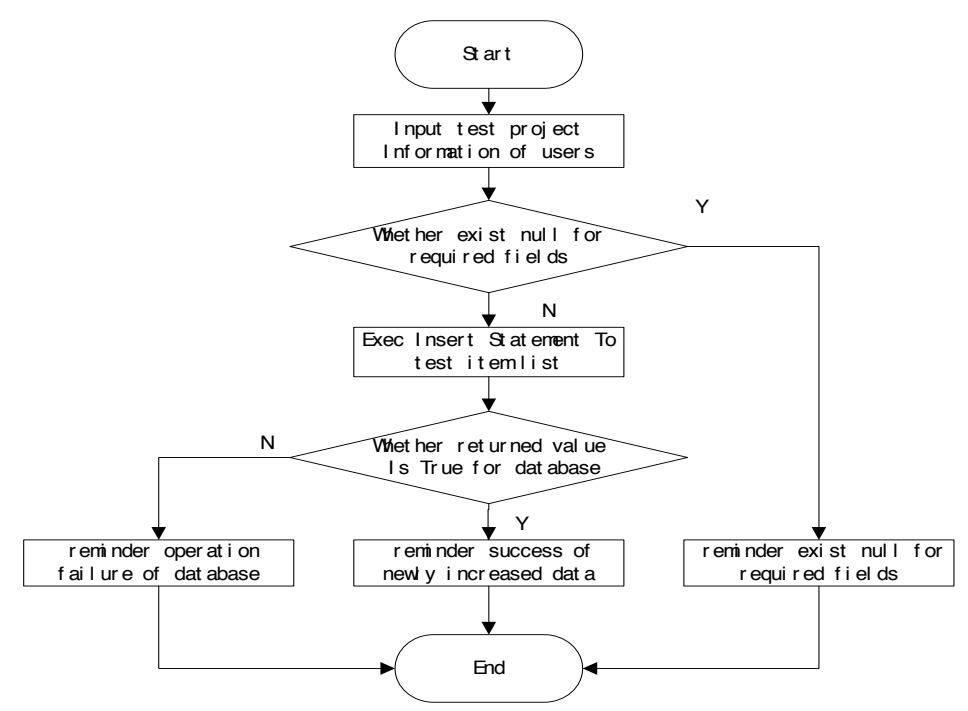

Fig. 5. Program flow for newly increased test project

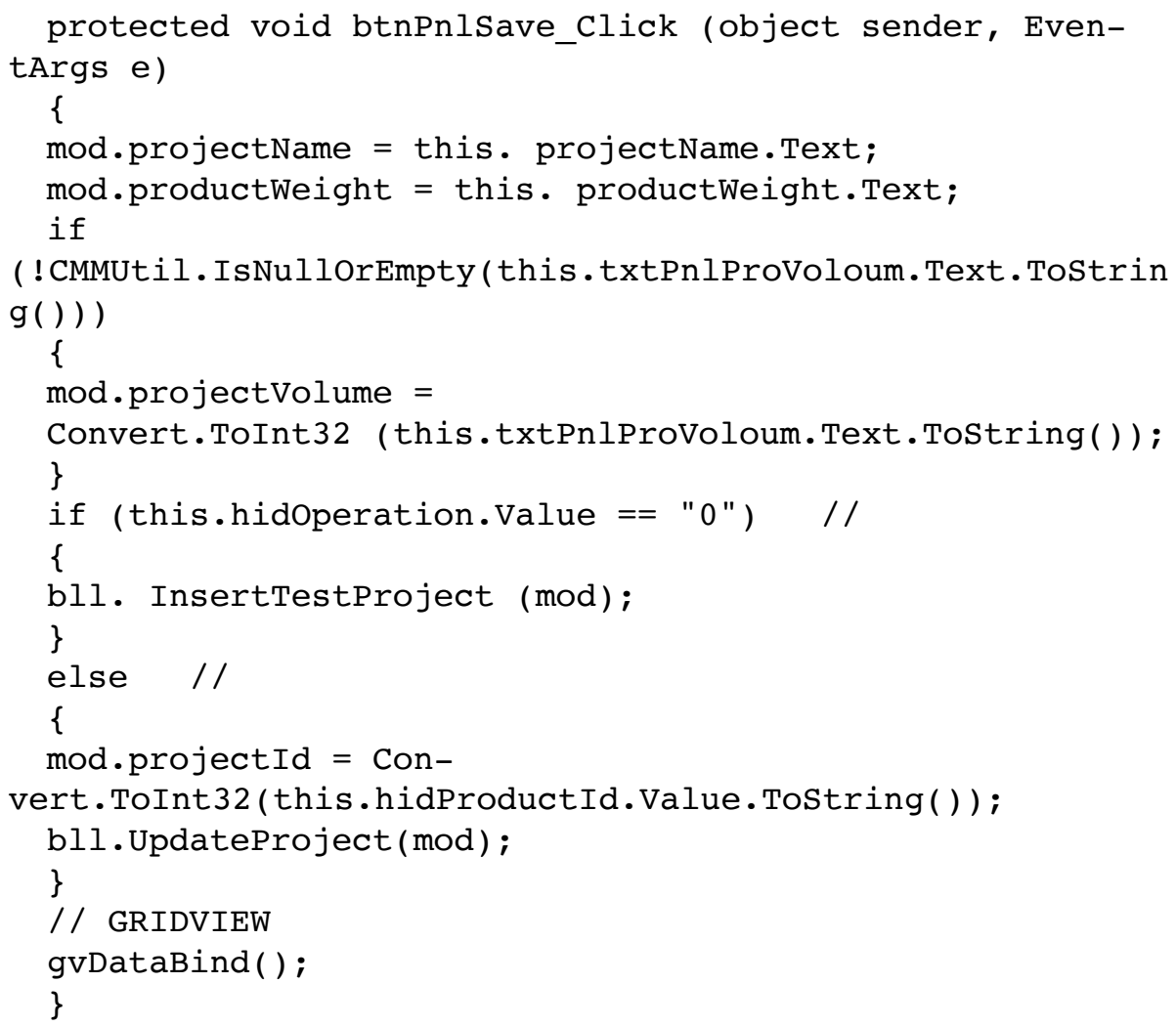


Score Management: The flow chart for the score entry function in the platform score management module is shown in Figure 6.

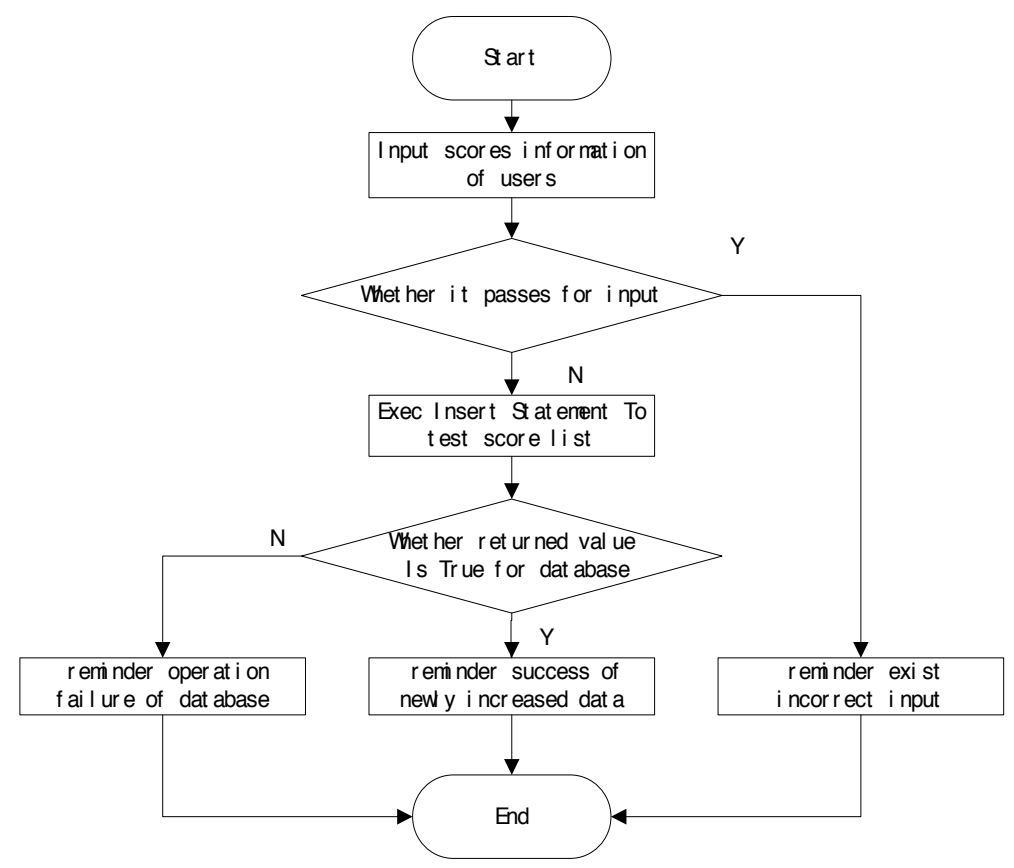

Fig. 6. Program flow for score input

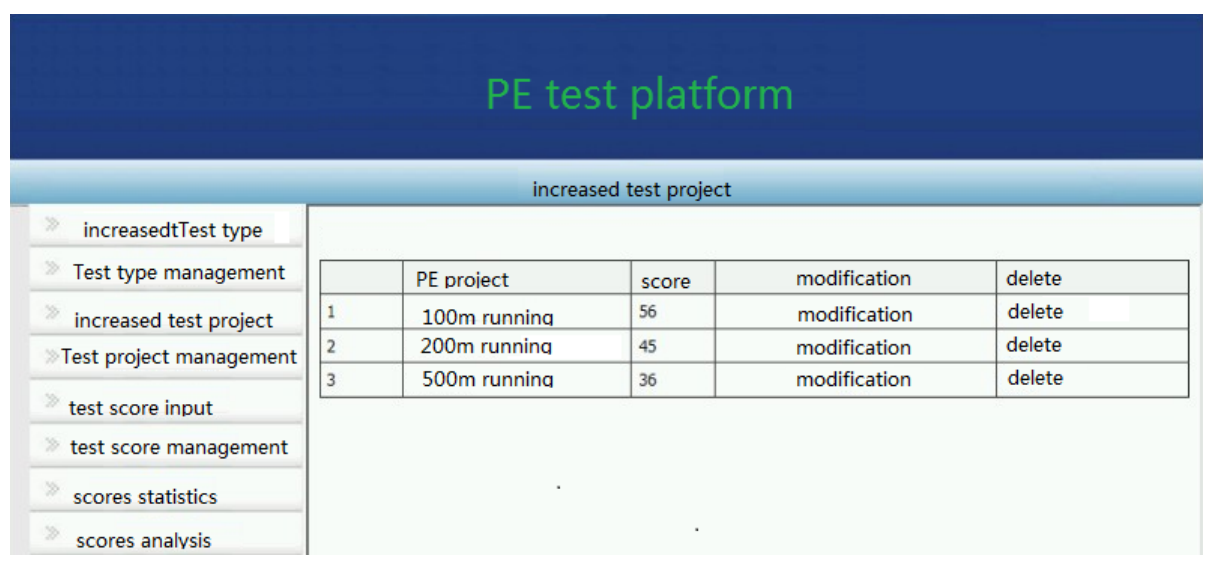

Fig. 7. platform interface of scores input for student

The interface for student score entry in the platform score management module is shown in Figure 7. 


\subsection{Implementation of data mining}

The P.E. performance examination table of a class is shown in Table 2.

Table 2. Score data table

\begin{tabular}{|l|l|c|c|c|c|c|c|c|c|}
\hline $\begin{array}{c}\text { Student } \\
\text { number }\end{array}$ & Name & $\begin{array}{c}\text { Long } \\
\text { jump }\end{array}$ & $\begin{array}{c}\text { Long } \\
\text { distance } \\
\text { running }\end{array}$ & Basketball & Sprint & Hurdles & Volleyball & Shot & Jump \\
\hline 0108012 & Cai LY & 77 & 71 & 68 & 71 & 81 & 81 & 73 & 86 \\
\hline 0108014 & Cao Q & 70 & 65 & 63 & 72 & 74 & 85 & 85 & 90 \\
\hline 0108002 & Che YX & 59 & 81 & 67 & 87 & 80 & 76 & 63 & 86 \\
\hline 0108003 & Chen DQ & 69 & 84 & 71 & 61 & 78 & 74 & 59 & 86 \\
\hline 0108010 & Cheng J & 72 & 76 & 72 & 64 & 72 & 71 & 69 & 91 \\
\hline 0108001 & Luo CX & 69 & 80 & 66 & 58 & 67 & 80 & 61 & 81 \\
\hline 0108026 & Ma L & 70 & 81 & 78 & 52 & 79 & 65 & 58 & 91 \\
\hline 0108038 & Meng YC & 78 & 78 & 47 & 60 & 56 & 76 & 70 & 87 \\
\hline 0108011 & Ning SL & 61 & 68 & 63 & 74 & 67 & 76 & 58 & 79 \\
\hline 0108008 & Qiu JD & 70 & 73 & 73 & 49 & 60 & 74 & 60 & 82 \\
\hline 0108019 & Pang HD & 62 & 71 & 59 & 69 & 66 & 66 & 67 & 83 \\
\hline 0108007 & Pu JY & 74 & 85 & 64 & 60 & 73 & 77 & 48 & 69 \\
\hline
\end{tabular}

Step 1: Two worksheets need to be created, titled the original worksheet and the original conversion table, respectively. The former is used to list the P.E. scores of all the students in this P.E. exam and the latter is used to list all the exam items. For now, 9 are chosen as attributes. Fail is denoted as 0 and pass as 1.

Step 2: The training set is collated. The training set mainly contains the comparison of the statistical results about the number of students who pass and fail the exam, as shown in Table 3.

Table 3. Training data sets

\begin{tabular}{|l|c|c|c|c|c|c|c|c|}
\hline & $\begin{array}{c}\text { Long } \\
\text { jump }\end{array}$ & $\begin{array}{c}\text { Long distance run- } \\
\text { ning }\end{array}$ & Basketball & Sprint & Hurdles & Volleyball & Shot & Jump \\
\hline $\begin{array}{l}\text { The passing num- } \\
\text { ber }\end{array}$ & 81 & 56 & 33 & 31 & 38 & 90 & 38 & 101 \\
\hline The fail number & 78 & 103 & 126 & 128 & 121 & 71 & 121 & 58 \\
\hline
\end{tabular}

Step 3: The information gain is calculated with the formula. Based on the calculation results, the best attribute of the instance can be selected from the training set.

Let's take the long jump for example to illustrate how to calculate the information gain. The calculation data are as follows:

$\mathrm{I}(\mathrm{P}, \mathrm{N})=-[(31 / 159) * \log 2(29 / 158)+(130 / 159) * \log 2(130 / 158)]=0.8021$

Where, $\mathrm{P}$ and $\mathrm{N}$ stand for the sprint performance record under two different states.

S11: long jump score $=1$ and sprint performance $=131$ records

S12: long jump score $=1$ and sprint performance $=61$ records

S21: long jump score $=0$ and sprint performance $=15$ records

S22: long jump score $=0$ and sprint performance $=181$ records

Then the score of long jump can be calculated as follows 
$\mathrm{E}($ long jump $)=(81 / 160) * \mathrm{I}(31,49)+(81 / 159) * \mathrm{I}(5,81)=0.7029$

The value of I $(\mathrm{P}, \mathrm{N})$ minus the score of long jump is the final information gain for long jump.

Gain (long jump) $=\mathrm{I}(\mathrm{P}, \mathrm{N})$ - E (long jump) $=0.0992$

The above calculation methods and calculation principles, also applied to other P.E. exam items. Through calculation and comparison of the information gains of several P.E. exam items, it can be seen that long-distance running has the highest information gain in the training set; in other words, the exam item that is most helpful to determining whether a sprint performance passes the exam in the training set is the long-distance running rather than long jump or basketball.

Step 4: For an exam item, after the information gain is calculated, the longdistance running, which has the highest information gain, is used as the root node in the decision tree. As the exam results of long-distance running are divided into pass and fail, the attribute values corresponding to the root node can also be divided into two types. When the decision tree is further created, two sub-nodes can be set up under the root node - long-distance running.

Through comparison and analysis of the P.E. exam data, the records where the student fails the long-distance running but passes the sprint can be screened out. If 0 represents fail and 1 represents 1 , that is to say, the long-distance running score is 0 while the sprint score is 1 , there are 4 records of such. These 4 records show that students who are poor at long-distance running are also poor at sprint. Sometimes the prediction accuracy can be up to $96 \%$, so if a student fails the long-distance running, it can be inferred that he or she may also fail the sprint. In this case, the attribute of failing long-distance running can be separated out on the decision tree and then the sprint can be regarded as the root note for the next round of splitting in other predictions.

Step 5: According to the above construction methods and principles, some preliminary conclusions can be drawn, which are summarized as follows:

- The sprint result is greatly affected by the long-distance running result. Usually a student who fails the long-distance running will also fail the sprint. The accuracy of this prediction is (104-4)/104=96.2\%.

- If a student passes the long-distance running exam but at the same time fails the hurdle exam, then the student is very likely to fail the sprint exam. The accuracy of this prediction is $(32-6) / 32=81.3 \%$.

- If a student passes the long-distance running exam and also passes the hurdle ex$\mathrm{am}$, then he or she will usually pass the sprint, and the accuracy is $(25-3) / 25=88 \%$.

In running exams, long-distance running and sprint are correlated, and in most cases, positively correlated, which means, the sprint performance can be predicted from the long-distance running performance. If a student is good at long-distance running, he or she will not be poor at sprinting; if the student fails the long-distance running, he or she will usually fail the sprint exam, too. The practice of hurdling more or less influences the sprint performance. So in summary, when a P.E. teacher trains students who are poor at running, the teacher should focus more on the long-distance running training of this student in daily exercise. When the student gets better at long-distance 
running, he or she will improve in sprinting accordingly. And for those students who are good at long-distance running but not so good at sprinting, the teacher should ask them to take more training in hurdling to improve their sprint abilities.

\section{Conclusion}

- In the design and development of the computer-data-analysis-based P.E. assessment platform, this paper adopts the ASP.NET technology and employs the threelayer architecture to achieve the automated information-based management on P.E. scores. After each P.E. exam, this platform can scientifically analyze and process the scores, so it can greatly reduce P.E. teachers' workload and at the same time make the exam results more useful because these result can help students develop good physical exercise habits and strengthen their physical fitness. In this way, the P.E. teaching quality can be guaranteed.

- In the design of the platform, this paper also uses the decision tree theory and the ID3 algorithm to conduct statistical analysis of the scores obtained in the college P.E. examination, and then employs the data mining technology to carry out scientific prediction and analysis to provide advice and suggestions for making college P.E. teaching more practical and scientific.

\section{Acknowledgement}

This paper is supported by The Program Supported by Educational Department of Sichuan Province: The Research on the Current situation and Intervention Measures of College Students' lack of Health Knowledge (No.13SB0287); 2017 Research Project of Sichuan Province Education Department: "Research on the Construction of Teacher teams in Local Universities under the Background of Transformation and Development-illustrated by the Case of Sichuan Province", (No.17SB0615).

\section{References}

[1] Carlson, S. A., Fulton, J. E., Lee, S. M., Maynard, L. M., Brown, D. R., Rd, K. H., et al. (2008). Physical education and academic achievement in elementary school: data from the early childhood longitudinal study. American Journal of Public Health, 98(4): 721-727. https://doi.org/10.1016/s0162-0908(09)79480-2

[2] Byra, M., Karp, G. G. (2010). Data collection techniques employed in qualitative research in physical education teacher education. Journal of Teaching in Physical Education, 19(2): 246-266. https://doi.org/10.1123/itpe.19.2.246

[3] Dyson, B. (2002). The implementation of cooperative learning in an elementary physical education program. Journal of Teaching in Physical Education, 20(3): 69-85. https://doi.org/10.1123/jtpe.22.1.69

[4] Armour, K. M., Yelling, M. (2007). Effective professional development for physical education teachers: the role of informal, collaborative learning. Journal of Teaching in Physical Education, 26(2), 177-200. https://doi.org/10.1123/jtpe.26.2.177 
[5] Tannehill, D., Others, A. (1994). Attitudes toward physical education: their impact on how physical education teachers make sense of their work. Journal of Teaching in Physical Education, 13(4): 406-420. https://doi.org/10.1123/itpe.13.4.406

[6] Panzarini, S. R., Pedrini, D., Brandini, D. A., Poi, W. R., Santos, M. F., Correa, J. P. T., et al. (2005). Physical education undergraduates and dental trauma knowledge. Dental Traumatology, 21(6): 324-8. https://doi.org/10.1111/j.1600-9657.2005.00327.x

[7] Trost, S. G. (2004). School physical education in the post-report era: an analysis from public health. Journal of Teaching in Physical Education, 23(4), 318-337. https://doi.org/10.1123/itpe.23.4.318

[8] Escartí, A., Gutiérrez, M. (2001). Influence of the motivational climate in physical education on the intention to practice physical activity or sport. European Journal of Sport Science, 1(4): 1-12. https://doi.org/10.1080/17461390100071406

[9] Sebren, A. (2010). Preservice teachers' reflections and knowledge development in a fieldbased elementary physical education methods course. Journal of Teaching in Physical Education, 14(3), 262-283. https://doi.org/10.1123/jtpe.14.3.262

[10] Tassitano, R. M., Barros, M. V. G., Tenório, M. C. M., Bezerra, J., Florindo, A. A., Reis, R. S. (2010). Enrollment in physical education is associated with health-related behavior among high school students. Journal of School Health, 80(3): 126-133. https://doi.org/10.1111/j.1746-1561.2009.00476.x

[11] Bernstein, E., Phillips, S. R., \& Silverman, S. (2011). Attitudes and perceptions of middle school students toward competitive activities in physical education. Journal of Teaching in Physical Education, 30(1): 69-83. https://doi.org/10.1123/itpe.30.1.69

[12] Kulinna, P. H., Scrabisfletcher, K., Kodish, S., Phillips, S. R., Silverman, S. (2009). A decade of research literature in physical education pedagogy. Journal of Teaching in Physical Education, 28(2): 119-140. https://doi.org/10.1123/itpe.28.2.119

[13] Martin, J. J., Kulinna, P. H. (2005). A social cognitive perspective of physical-activityrelated behavior in physical education. Journal of Teaching in Physical Education, 24(3): 265-281. https://doi.org/10.1123/jtpe.24.3.265

[14] Parker, J. (2010). Secondary teachers' views of effective teaching in physical education. Journal of Teaching in Physical Education, 14(2): 127-139. https://doi.org/10.1123/jtpe.14.2.127

[15] Kinchin, G. D., O'Sullivan, M. (2003). Incidences of student support for and resistance to a curricular innovation in high school physical education. Journal of Teaching in Physical Education, 22(3): 245-260. https://doi.org/10.1123/jtpe.22.3.245

\section{Authors}

Fan Cheng is a lecturer in Physical Education College of Yibin University. He has a master's degree. Now he is the director of the teaching and research department in Yibin college, and he is mainly engaged in sports science research and sports teaching.

Yiwei Yin is an associate researcher, and works in the personnel department of Yibin college. His main research interests are human resource management and development, sports humanities and sociology.

Article submitted 2019-01-15. Resubmitted 2019-02-23. Final acceptance 2019-02-27. Final version published as submitted by the authors. 